\title{
ANÁLISE DE IMAGENS DE TEXTOS DE DIVULGAÇÃO CIENTÍFICA INSERIDOS EM LIVROS DIDÁTICOS DE BIOLOGIA
}

\author{
Pedro Henrique Ribeiro de Souza ${ }^{1}$ \\ Marcelo Borges Rocha
}

\begin{abstract}
RESUMO
Os livros didáticos (LDs) de Ciências e de Biologia apresentam textos inseridos provenientes da Divulgação Científica (DC), cujas imagens podem destoar das originais, inclusive com significado diferente. Este trabalho analisou 31 imagens em 27 textos de DC relativos à Biologia animal, presentes em sete LDs de Biologia para o Ensino Médio. De acordo com a classificação semiótica e conceitual, foi possível perceber que a maioria das imagens possui caráter naturalista, quando há proximidade com o real, e simbólico, conferindo atmosfera para os textos. Identificou-se maior interação ou contraste na relação entre as informações do texto e a imagem. A conotação fotográfica mais recorrente foi a pose, privilegiando atitudes estereotipadas dos animais. Percebeu-se alteração de significado em diversas imagens em relação aos textos originais. Estas diferenças podem estar relacionadas com intenções didáticas dos autores dos LDs, que promovem um distanciamento destas imagens com aquelas presentes na parte didática dos LDs.
\end{abstract}

Palavras-chave: divulgação científica; livro didático; ensino de biologia; imagens.

\section{IMAGE ANALYSIS OF POPULAR SCIENCE TEXTS INSERTED IN BIOLOGY TEXTBOOKS}

\begin{abstract}
Science and Biology textbooks have inserted Popular Science texts, whose images can undo the original ones, including different purpose. This work analyzed 31 images from 27 Popular Science texts related to animal biology, in seven High School Biology textbooks. According to semiotics and conceptual classification, we noticed that most of images have both naturalist trace, close to reality, and symbolic trace, conferring atmosphere to these texts. We identified more interaction and contrast in relation between text information and image. Photographic connotation most recurrent was pose, privileging animal stereotype attitudes. We noticed purpose alterations in many images compared to originals. These differences can be related to didactic intentions from textbooks authors, promoting a distance between those images from the ones into didactic sections in textbooks.
\end{abstract}

Keywords: popular science; textbook; biology teaching; images.

Recebido em: $13 / 8 / 2018$

Aceito em: $11 / 6 / 2020$

\footnotetext{
1 Autor correspondente. Colégio Pedro II. Avenida Marechal Floriano, 80 - Centro. Rio de Janeiro/RJ, Brasil. CEP 20080-001. http://lattes. cnpq.br/6176522509594223. https://orcid.org/0000-0002-2365-8804. pedrohrsouza@gmail.com

2 Centro Federal de Educação Tecnológica Celso Suckow da Fonseca. Rio de Janeiro/RJ, Brasil. http://lattes.cnpq.br/5640018108479090. https://orcid.org/0000-0003-4472-7423.
} 


\section{INTRODUÇÃO}

A utilização de textos de Divulgação Científica (DC) no âmbito do Ensino de Ciências configura uma prática apoiada por diversos autores, por representar uma forma de contextualizar os conhecimentos científicos presentes nos conteúdos disciplinares, contribuindo para o incentivo à prática da leitura de textos científicos, familiarizando-se com terminologias e conceitos da Ciência. No universo de produções acadêmicas que realizam a ponte entre DC e o Ensino de Ciências, destacam-se trabalhos que: buscaram a opinião de professores sobre a forma como estes usam publicações de DC em suas aulas (ROCHA, 2010); realizaram levantamentos das produções que tratam do uso de textos de DC em sala de aula (SOUZA; ROCHA, 2014b); ou analisaram artigos de DC de acordo com certas temáticas, como Biologia Celular (MONERAT; ROCHA, 2015), meio ambiente (GARRÉ; HENNING, 2015) e Sistemática Filogenética (SOUZA; ROCHA, 2015a).

Em outros trabalhos investigou-se, de forma pontual, como textos de DC são reelaborados ao serem inseridos em livros didáticos (LD) (MARTINS; CASSAB; ROCHA, 2001; GALIETA-NACIMENTO, 2005; SOUZA; ROCHA, 2014a). Esta inserção deve-se à prerrogativa dos autores e/ou editores dos LDs em tornar suas obras mais atrativas e contextualizadas, objetivando maior diversidade de fontes de informação. Atuam, também, como motivadores ou como forma de contextualização e de complementação dos conteúdos detalhados nos diferentes capítulos. Deve-se entender, no entanto, por que e de que maneira estes textos foram selecionados e adaptados ao serem incorporados pelos LDs. Conforme Martins e Damasceno (2002) relatam em sua análise de LDs de Ciências, a maioria dos textos de DC inseridos, sejam estes oriundos de jornais ou revistas, sofreu alguma espécie de adaptação, sugerindo um esforço de didatização.

O objetivo deste trabalho é analisar as imagens que acompanham os textos de DC inseridos em LDs de Biologia para o Ensino Médio, considerando também as possíveis alterações de significado que podem ocorrer pelas imagens substituídas. As imagens compõem o texto, representando um recurso fundamental que também será considerado para as concepções de natureza da ciência transmitidas, uma vez que sua leitura pode influenciar o leitor. Nesta análise investigamos como a mudança no sentido das imagens, provocada pela inserção do texto de DC no LD, pode interferir em sua leitura e suas possíveis consequências para o ensino.

\section{IMAGENS EM TEXTOS DE DIVULGAÇÃO CIENTÍFICA}

O texto científico constitui-se um híbrido semiótico, por utilizar elementos verbais e recursos pictóricos no mesmo espaço. Às imagens podem ser atribuídas as seguintes funções, de acordo com Martins (1997, p. 297): “atrair atenção, provocar interesse, motivar; sinalizar e organizar o conteúdo por vir; ilustrar uma ideia ou argumento; e (...) descrever um procedimento".

As imagens são representações do mundo, que é dividido em dois domínios: 
o domínio das imagens como representações visuais que são as pinturas, gravuras, desenhos, fotografias e imagens televisivas, cinematográficas, holo e infográficas - neste domínio estão as imagens consideradas objetos materiais e signos que representam o meio visual; e o domínio imaterial que é o domínio da mente - aqui as imagens são visões, fantasias, imaginação e esquemas de representação mentais (PIMENTA; GOUVÊA, 2009, p. 2).

Barthes (1990) considera que um mesmo signo pode abrigar diferentes sentidos para diferentes leitores, o que caracteriza a natureza polissêmica da imagem e pressupõe a existência de uma "cadeia flutuante de significados", quando o leitor opta por alguns e ignora os outros possíveis. Para o autor, caberia ao enunciador o papel de conter essa cadeia de proliferação de sentidos utilizando vários recursos de retórica a fim de evitar o que definiu como o "terror dos signos incertos". Para este autor, toda representação iconográfica tem seu referente no mundo real, representando aquilo que está fora de si e que deseja comunicar. As imagens constituem representações que podem se aproximar mais ou menos da realidade, por exemplo, a fotografia, que pode ser considerada "a representação icônica que apresenta o maior grau de iconicidade, ou seja, de semelhança com o seu referente" (PRALON, 2012, p. 166).

Por conta desta característica polissêmica da imagem, é necessário, portanto, que existam metodologias que permitam o aprender a ler imagens,

pois, do mesmo modo que a linguagem verbal é desenvolvida em nosso contato com o mundo, que nos alfabetiza para participarmos do processo de comunicação, a capacidade de leitura e construção de imagens também depende de uma alfabetização visual (REGO, 2012, p. 174).

Na mídia impressa, as imagens que acompanham o texto escrito representam uma forma de comunicação estética, permitindo uma pausa durante a leitura para reflexões, sendo percebidas de forma unívoca pelas pessoas, ou seja, cada uma tem sua leitura de imagens. Esta imagem que representa uma ideia pode ser "fiel ao texto ou o texto pode esclarecê-la; pode ir além do texto ou simplesmente decorar o texto" (GOUVÊA; MARTINS, 2001, p. 56).

De acordo com Pimenta e Gouvêa (2009), as imagens presentes nas publicações de DC são signos científicos relevantes, fornecendo subsídios para o aprendizado de determinados conhecimentos científicos. Os esquemas podem atrair o interesse do leitor, auxiliando na fixação e compreensão do conteúdo presente na matéria. Com isso, é importante analisar também as imagens presentes nestes artigos selecionados. As imagens também são fontes ricas para investigar os acontecimentos ou para transmitir ideias e difundir determinados discursos, em especial as veiculadas pela mídia (MARANHÃO, 2008). É de consenso, portanto, que se aprenda a ler estas imagens, ou seja, compreender as estruturas da mensagem transmitida pela imagem. 
Grillo (2009) analisou as imagens de capa de artigos da Scientific American Brasil, cuja função é representar uma síntese do conteúdo abordado nesta matéria. A autora concluiu não só que a imagem cumpre este papel de resumir, de forma objetiva, o ponto principal da matéria de capa, mas que representa uma visão da própria revista a respeito do progresso do conhecimento científico.

Carvalho (2010) investigou as matérias de capa sobre a mesma temática - pílulas que aumentariam a capacidade de memorizar - em duas revistas diferentes: a Superinteressante e a Scientific American Brasil. A autora analisou as imagens da capa e do corpo do texto, bem como a linguagem, as entrevistas com pesquisadores ou cidadãos comuns e as referências utilizadas pelos autores das matérias, como a revista Nature. Ao final, a autora percebe a diferença clara entre a linguagem adotada na Superinteressante, mais acessível e voltada para o cotidiano do leitor, em geral leigo, e a adotada na Scientific American Brasil, com uso maior de termos científicos, ideal para um público com maior apropriação destes termos.

\section{TEXTOS DE DC NO LD DE CIÊNCIAS}

O LD é objeto fundamental adotado no processo da educação e caracteriza-se por ser uma obra aberta, que deve dialogar com outros tipos de saberes, como os da comunidade científica. Nesse sentido, surgem iniciativas como o Programa Nacional do Livro Didático (PNLD), que foi regulamentado pelo Ministério da Educação a partir dos anos 80 do século 20 para garantir que o material fosse adequado ao processo de ensino-aprendizagem (BIZZO, 2000). Apesar de considerada uma escolha pouco democrática, o PNLD apresenta grandes benefícios no contexto da educação pública brasileira, pois tornam acessíveis materiais didáticos importantes no processo de ensino-aprendizagem e que os estudantes das escolas públicas dificilmente poderiam adquirir. Além disso, a escolha dos LDs é feita em um universo de livros avaliados e recomendados por equipes que combinam especialistas em educação e nas disciplinas específicas, garantindo um patamar de qualidade aceitável para as obras adquiridas (EL-HANI; ROQUE; ROCHA, 2007).

A pesquisa acerca dos LDs de Ciências teve início na década de 70 com um enfoque de natureza crítica, em especial relacionada aos LDs como "detentores de verdades", o que foi estimulado pela sua importância historicamente construída nas escolas, entre os professores e os documentos públicos. Dessa forma, busca-se uma análise dos conceitos veiculados pelos LDs, no sentido de discuti-los e ressignificá-los (GÜLLICH; EMMEL; PANSERA-DE-ARAÚJO, 2009). Para Garcia e Bizzo (2010), é importante superar o senso comum de que é simples realizar estudos sobre os LDs e que todas as ferramentas teóricas para realizar essa tarefa estão disponíveis, considerando ser importante compreender de que maneira o professor de Ciências utiliza os LDs em sala de aula.

Mesmo com a instituição do PNLD, permanecem os erros cometidos por alguns autores de LDs de Ciências, seja de natureza conceitual ou textual, no uso de simplificações, linguagem infantilizada, discriminação, generalizações, analogias, metáforas, entre outros recursos (BELLINI, 2006; GÜLLICH; EMMEL; PANSERA-DE-ARAÚJO, 2009). Em 
certos casos, os LDs são elaborados para um aluno genérico, que não existe, cabendo aos professores saber escolher a obra que melhor se insere no contexto de sua realidade escolar, adaptando-a conforme sua necessidade (NúÑEZ et al., 2003). Existe, entretanto, uma escassez de indicações e testes de instrumentos que orientem o professor na escolha dos LDs, bem como não há espaço para expor suas críticas a respeito das coleções (VASCONCELOS; SOUTO, 2003). Alguns autores, como Megid Neto e Fracalanza (2003) e Núñez et al. (2003), relacionam os principais elementos dos LDs que possam guiar essa escolha, como a ausência de erros conceituais e a exposição dos conceitos de forma clara e motivadora, introduzindo espaços para o aluno participar do processo do ensino-aprendizagem mais como sujeito do que como objeto.

No âmbito das análises dos LDs, surgem aquelas que estudam a forma como estes inserem materiais de DC, sejam fragmentos ou textos completos (MARTINS; DAMASCENO, 2002; SOUZA; ROCHA, 2015b). A inserção dos textos de DC nos LDs deve-se à prerrogativa dos autores e/ou editores de tornar suas obras mais atrativas e contextualizadas, objetivando maior diversidade de fontes de informação. Assim, estes textos atuam como motivadores ou como forma de contextualização e de complementação dos conteúdos detalhados nos diferentes capítulos. Deve-se procurar entender, no entanto, por que e de que maneira estes textos foram selecionados e adaptados ao serem incorporados nos LDs. Martins e Damasceno (2002) sugerem que a maioria dos textos de DC incorporados, sejam estes oriundos de jornais ou revistas, sofreu alguma espécie de adaptação, sugerindo um esforço de torná-los didáticos.

Martins, Cassab e Rocha (2001) e Souza e Rocha (2014a) identificaram inúmeras alterações para tornar a linguagem do texto compatível com o nível de ensino para o qual o LD é destinado, havendo redução significativa de informação, inclusive com modificação da visão de natureza da ciência transmitida. Neste mesmo âmbito, Galieta-Nacimento (2005) observou que o texto adaptado passou a integrar o gênero textual do LD, de modo que não apenas sua composição linguística se altera, como também seu público-alvo e objetivos. Deste modo, o texto de DC assume o papel de mais um elemento composicional do LD com a função central de contextualizar os assuntos. Em trabalhos anteriores (SOUZA; ROCHA, 2017, 2018), analisamos de forma mais aprofundada estas adaptações e constatamos que o texto de DC inserido no LD não é um texto divulgativo ou didático, mas sim um híbrido que conserva elementos de ambos os textos.

No que respeita às imagens que acompanham estes textos de $D C$, poucos trabaIhos descrevem, de forma pouco aprofundada, como as alterações em nível textual refletem-se no conteúdo imagético. Em um destes, Martins, Cassab e Rocha (2001) identificaram a redução drástica do número de imagens de um texto de DC adaptado para o LD. Além disto, houve substituição das fotografias e diminuição da diversidade de funções das imagens, que apresentavam função apenas ilustrativa, ao invés de acrescentar informação e detalhe, exemplificar ou explicar por meio da visualização. Souza e Rocha (2014a) também encontraram redução no número de imagens, porém perceberam que a imagem remanescente no texto didático ganhou função informativa, devido à escolha de uma fotografia que contextualizou melhor a temática do texto e a sua legenda, o que 
contrastou com a pesquisa anteriormente citada. Identificar, portanto, a diminuição do número de imagens bem como as possíveis alterações se justifica no que se refere à caracterização da estrutura do LD que transforma o texto de DC em um híbrido (SOUZA; ROCHA, 2018).

\section{METODOLOGIA}

Selecionou-se 60 textos de DC extraídos de sete coleções de LDs de Biologia do Ensino Médio, todas recomendadas pelo Programa Nacional do Livro Didático (PNLD) (BRASIL, 2014). Optou-se por analisar apenas as imagens cujos textos estivessem relacionados à Biologia Animal, recorte já utilizado em outras pesquisas dos autores (SOUZA, 2017; SOUZA; ROCHA, 2017, 2018). As coleções de Bizzo (2013) e de Linhares e Gewandsznajder (2013) não foram contempladas nesta análise, por que não apresentaram textos de DC sobre a temática analisada. O Quadro 1 apresenta as principais informações sobre cada LD.

Quadro 1 - Principais informações a respeito das nove coleções didáticas utilizadas

\begin{tabular}{|l|l|c|c|c|}
\hline \multicolumn{1}{|c|}{ Coleção } & \multicolumn{1}{|c|}{ Autores } & Editora & \multicolumn{1}{c|}{ Edição } & $\begin{array}{c}\text { No de } \\
\text { textos }\end{array}$ \\
\hline Bio & LOPES; ROSSO (2013) & Saraiva & 2a de 2013 & 6 \\
\hline Biologia & CÉSAR; SEZAR; CALDINI JR.(2013) & Saraiva & 11a de 2013 & 6 \\
\hline Biologia & MENDONÇA (2013) & AJS & 2a de 2013 & 12 \\
\hline Biologia em contexto & AMABIS; MARTHO (2013) & Moderna & 1a de 2013 & 7 \\
\hline $\begin{array}{l}\text { Biologia Unidade e } \\
\text { Diversidade }\end{array}$ & FAVARETTO (2013) & Saraiva & 1a de 2013 & 13 \\
\hline Conexões em Biologia & BRÖCKELMANN (2013) & Moderna & 1a de 2013 & 11 \\
\hline $\begin{array}{l}\text { Ser Protagonista - } \\
\text { Biologia }\end{array}$ & OSORIO (2013) & SM & 2a de 2013 & 5 \\
\hline
\end{tabular}

Fonte: PNLD/2015 (BRASIL, 2014).

Neste trabalho a análise das imagens utilizou as classificações de imagens de Kress e Van Leeuwen (1996), de acordo com sua natureza semiótica e conceitual, a exemplo de Martins et al. (2003) e Piccinini (2012); consideradas as categorias propostas por Joly (2007) e Barthes (1990), adotadas por Pimenta e Gouvêa (2009), da relação entre o texto verbal e a imagem; e, para as fotografias, este trabalho também se baseou nos procedimentos de conotação fotográfica propostos por Barthes (1990) e adotados por Pimenta e Gouvêa (2009), que consistem na imposição de um sentido a partir da mensagem inerente à fotografia. As categorias de análise estão resumidas no Quadro 2. Quanto à alteração de significado das imagens, confrontamos os elementos presentes nas imagens do texto original de DC com aquelas do texto inserido no LD, identificando suas principais semelhanças e diferenças. 
Quadro 2 - Categorias de análise imagética adotadas neste trabalho

\begin{tabular}{|c|c|c|}
\hline Análise & Categoria & Definição \\
\hline \multirow{2}{*}{$\begin{array}{l}\text { Natureza semiótica } \\
\text { (KRESS; VAN } \\
\text { LEEUWEN, 1996) } \\
\end{array}$} & Naturalista & Representação do real, como fotografias. \\
\hline & Abstrata & Modelos teóricos. \\
\hline \multirow{4}{*}{$\begin{array}{l}\text { Natureza } \\
\text { conceitual } \\
\text { (KRESS; VAN } \\
\text { LEEUWEN, 1996) }\end{array}$} & Analítica & Relação entre parte e todo. \\
\hline & Classificatória & $\begin{array}{l}\text { Organizam membros de uma mesma classe para } \\
\text { uma leitura comparativa. }\end{array}$ \\
\hline & Simbólica & $\begin{array}{l}\text { Elementos que indicam propriedades específicas, } \\
\text { conferem aura ou atmosfera. }\end{array}$ \\
\hline & Narrativa & $\begin{array}{l}\text { Apresentam uma cadeia de ações, eventos ou } \\
\text { processos. }\end{array}$ \\
\hline \multirow{6}{*}{$\begin{array}{l}\text { Relação entre } \\
\text { imagem e texto } \\
\text { (JOLY, 2007; } \\
\text { BARTHES, 1990) }\end{array}$} & Exclusão/ Interação & $\begin{array}{l}\text { A imagem não exclui a linguagem, pois esta a } \\
\text { acompanha sob a forma de comentários, títulos } \\
\text { ou legendas. }\end{array}$ \\
\hline & Verdade/ Mentira & $\begin{array}{l}\text { A imagem pode ser verdadeira ou mentirosa } \\
\text { devido ao que é informado sobre o que esta } \\
\text { representa, podendo esta representação ser ou } \\
\text { não verdadeira. }\end{array}$ \\
\hline & $\begin{array}{l}\text { Interação/ } \\
\text { Complementaridade }\end{array}$ & $\begin{array}{l}\text { O texto pode indicar a forma correta de se ler } \\
\text { a imagem (ancoragem); criar uma expectativa } \\
\text { acerca da imagem futura (suspensão); o texto } \\
\text { cria uma alusão à imagem, mas esta nega o que } \\
\text { é apresentado (alusão); o texto dá informações } \\
\text { acerca de uma imagem (contraponto). }\end{array}$ \\
\hline & Revezamento & $\begin{array}{l}\text { Em geral aplicada em charges ou no cinema, } \\
\text { quando uma imagem perde o sentido se isolada } \\
\text { de outras e do texto, configurando-lhe uma ação. }\end{array}$ \\
\hline & Símbolo & $\begin{array}{l}\text { Imagens simbólicas que transmitem noções e } \\
\text { valores abstratos. }\end{array}$ \\
\hline & Imagem/ Imaginário & $\begin{array}{l}\text { Casos em que filmes narram histórias de fotografias } \\
\text { ou pinturas, onde imagens originam palavras que, } \\
\text { por sua vez, originam imagens. }\end{array}$ \\
\hline \multirow{6}{*}{$\begin{array}{c}\text { Conotação } \\
\text { fotográfica } \\
\text { (BARTHES, 1990) }\end{array}$} & Trucagem & $\begin{array}{l}\text { Intervém na imagem de modo a aproximar } \\
\text { elementos de caráter distinto. }\end{array}$ \\
\hline & Pose & $\begin{array}{l}\text { Valorização de atitudes estereotipadas para emitir } \\
\text { significados ao leitor. }\end{array}$ \\
\hline & Objeto & $\begin{array}{l}\text { Valorização de um objeto que se torna essencial } \\
\text { para estabelecer uma sintaxe na leitura da } \\
\text { imagem. }\end{array}$ \\
\hline & Fotogenia & Valorização da beleza da imagem \\
\hline & Estetismo & $\begin{array}{l}\text { Quando uma fotografia é transformada em uma } \\
\text { pintura. }\end{array}$ \\
\hline & Sintaxe & $\begin{array}{l}\text { O significado se encontra no nível do } \\
\text { encadeamento, como em uma história em } \\
\text { quadrinhos. }\end{array}$ \\
\hline
\end{tabular}

Fonte: Os autores.

\section{RESULTADOS E DISCUSSÃO}


Identificou-se 31 imagens, presentes em 27 textos de DC inseridos nos LDs, conforme descreve o Quadro 3. Houve redução significativa deste número, pois encontrou-se 107 imagens nos artigos originais. Na comparação, apenas três imagens que aparecem no texto original foram mantidas nos LDs, enquanto as demais não possuem correspondência. Houve inclusão de imagens, pelos autores e/ou editores dos LDs, em cinco textos, cujos originais não as apresentavam.

Quadro 3 - Comparação entre as imagens presentes nos textos de DC inseridos nos LDs e as imagens presentes nos textos originais

\begin{tabular}{|l|c|c|l|c|c|c|c|c|}
\hline $\begin{array}{l}\text { Imagens } \\
\text { inseridas }\end{array}$ & $\begin{array}{l}\text { Amabis; } \\
\text { Martho }\end{array}$ & Bröckelmann & $\begin{array}{l}\text { César; } \\
\text { Sezar; } \\
\text { Caldini Jr. }\end{array}$ & Favaretto & $\begin{array}{l}\text { Lopes; } \\
\text { Rosso }\end{array}$ & Mendonça & Osorio & Total \\
\hline $\begin{array}{l}\text { Textos } \\
\text { inseridos }\end{array}$ & 2 & 3 & 4 & 4 & 2 & 9 & 7 & 31 \\
\hline $\begin{array}{l}\text { Textos } \\
\text { originais }\end{array}$ & 4 & 20 & 15 & 17 & 5 & 37 & 9 & 107 \\
\hline
\end{tabular}

Fonte: Os autores.

\section{1) Classificação das imagens}

O Quadro 4 apresenta, à luz de Kress e Van Leeuwen (1996), como as imagens foram classificadas nesta pesquisa.

Quadro 4 - Classificação das imagens de acordo com Kress e Van Leuwen (1996)

\begin{tabular}{|c|c|c|c|c|c|c|c|c|c|}
\hline \multicolumn{2}{|c|}{ Classificação } & \multirow{2}{*}{$\begin{array}{c}\begin{array}{l}\text { Amabis; } \\
\text { Martho }\end{array} \\
2\end{array}$} & \multirow{2}{*}{$\begin{array}{c}\text { Bröckelmann } \\
3\end{array}$} & \multirow{2}{*}{$\begin{array}{l}\text { César; } \\
\text { Sezar; } \\
\text { Caldini Jr. } \\
2\end{array}$} & \multirow{2}{*}{$\begin{array}{c}\text { Favaretto } \\
4\end{array}$} & \multirow{2}{*}{\begin{tabular}{|c|}
$\begin{array}{l}\text { Lopes; } \\
\text { Rosso }\end{array}$ \\
2 \\
\end{tabular}} & \multirow{2}{*}{$\begin{array}{c}\text { Mendonça } \\
7\end{array}$} & \multirow{2}{*}{$\begin{array}{c}\text { Osorio } \\
5\end{array}$} & \multirow{2}{*}{$\begin{array}{r}\text { Tota } \\
25\end{array}$} \\
\hline$\stackrel{\underline{v}}{5}$ & Naturalista & & & & & & & & \\
\hline 岕 & Abstrata & - & - & 2 & - & - & 2 & 2 & 6 \\
\hline \multirow{4}{*}{ 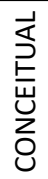 } & Simbólica & 2 & 3 & 4 & 3 & 1 & 7 & 5 & 25 \\
\hline & Classificatória & - & - & - & 1 & 1 & - & 1 & 3 \\
\hline & Narrativa & - & - & - & - & - & 1 & 1 & 2 \\
\hline & Analítica & - & - & - & - & - & 1 & 1 & 2 \\
\hline
\end{tabular}

Fonte: Os autores.

A classificação semiótica diz respeito ao potencial comunicativo da imagem em relação ao conteúdo que veicula. Nesta categoria, as imagens podem ser naturalistas, quando representam o real, ou abstratas, quando envolvem a representação de modelos teóricos. Assim, 25 imagens foram consideradas naturalistas, por serem fotografias, ao passo que as outras 6 são abstratas, incluindo duas ilustrações de tetrápodes primitivos que acompanham um texto da coleção de César, Sezar e Caldini Jr. (2013) (Figuras 1 e 2). 
Figura 1 - Representação do tetrápode primitivo Acanthostega

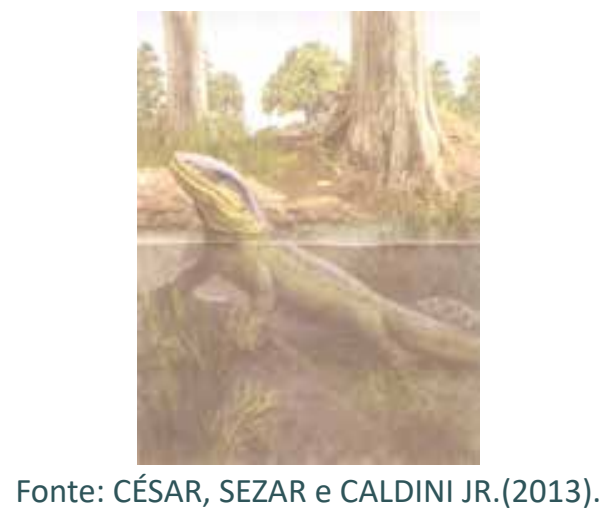

Figura 2 - Representação do tetrápode primitivo Ichthyostega

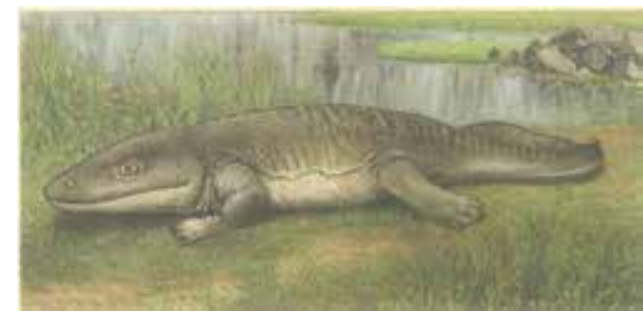

Fonte: CÉSAR, SEZAR e CALDINI Jr. (2013).

Quanto à classificação conceitual das imagens, percebe-se que 25 destas são representações simbólicas, isto é, "destacam elementos que indicam propriedades específicas, conferem aura ou atmosfera" (PICCININI, 2012, p. 155). Como exemplo, a Figura 3 , presente em um texto inserido na coleção de Bröckelmann (2013), que lida com o aluguel de polinizadores. A opção por esta fotografia é meramente ilustrativa, situando o leitor no universo das abelhas polinizadoras, isto é, fazendo-o associar o assunto tratado com a imagem destes animais cuja importância é descrita no texto. Três imagens foram classificadas como classificatórias, pois "organizam membros de uma mesma classe, privilegiando uma leitura comparativa" (PICCININI, 2012, p. 155). Nesta categoria, encontra-se a Figura 4, inserida na coleção de Osorio (2013), que representa uma filogenia de alguns primatas. Mesmo representando os animais por componentes verbais e não imagéticos, é possível compreender a posição filogenética de cada primata, o que influencia em sua classificação.

Figura 3 - Abelhas polinizadoras

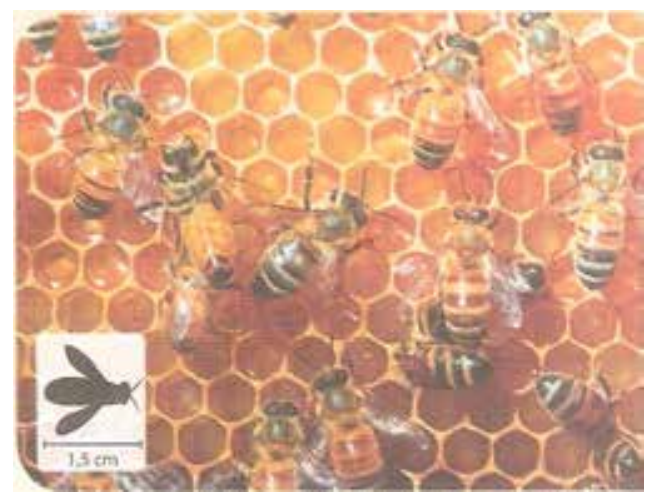

Fonte: BRÖCKELMANN (2013).
Figura 4 - Cladograma das relações evolutivas de alguns primatas

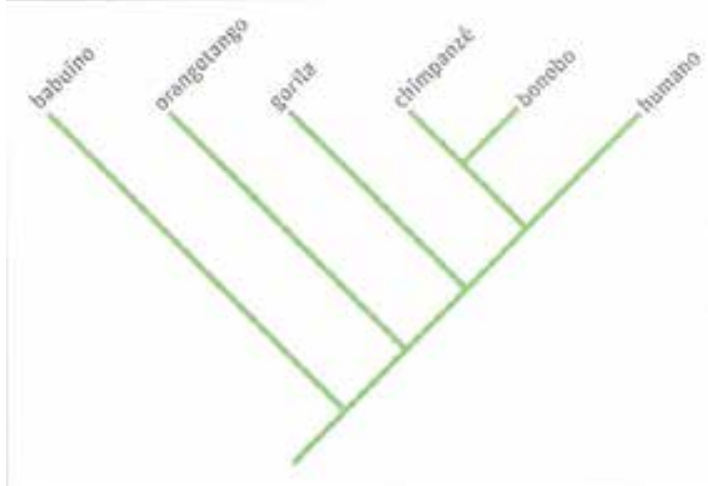

Fonte: OSORIO (2013).

Duas imagens foram categorizadas como narrativas, isto é, estabelecem uma sucessão de eventos, ações ou processos. A Figura 5, inserida na coleção de Mendonça (2013), exemplifica esta categoria, pois estabelece uma série de processos encadeados ao descrever como uma macaca em um laboratório nos Estados Unidos conseguiu comandar o movimento de um robô em outro laboratório no Japão. 
Figura 5 - Esquema que descreve um experimento envolvendo um macaco e um robô

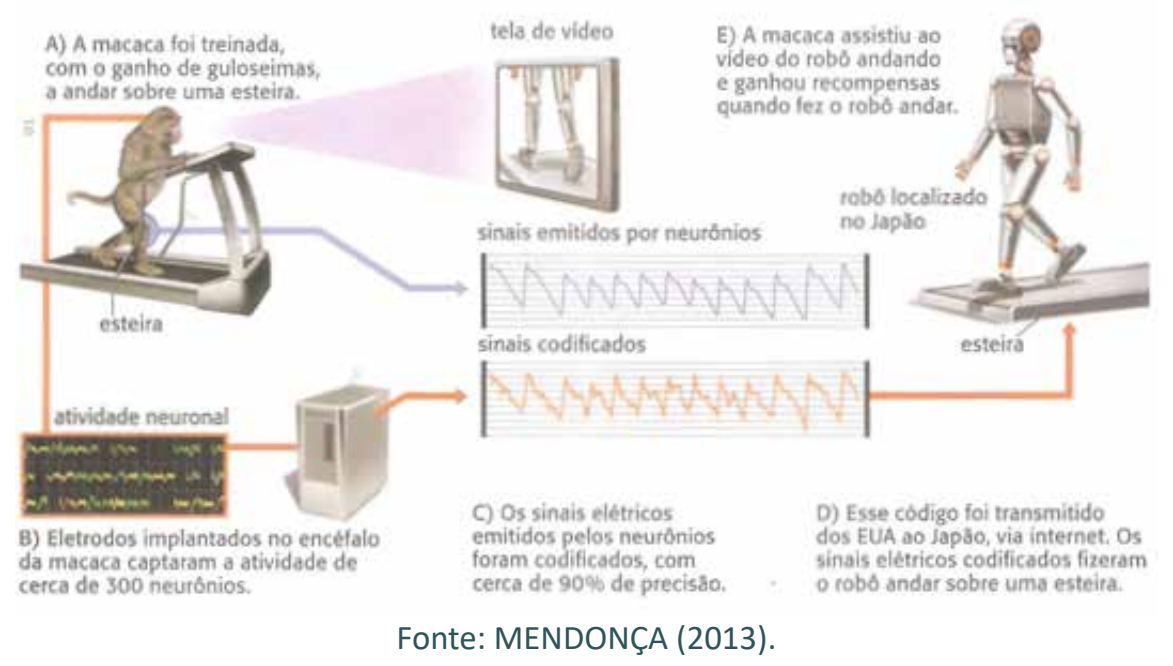

Duas imagens foram classificadas como analíticas, que estabelecem a relação entre a parte e o todo. Isto foi verificado na Figura 6, presente na coleção de Mendonça (2013), cuja lupa amplia a visão do pé do personagem Jeca Tatu, de Monteiro Lobato, revelando os vermes que por ali entram no organismo humano. A outra imagem nesta categoria é um mapa que situa o leitor a respeito da localização geográfica do Estado do Rio de Janeiro no mapa do Brasil, destacando a localização da bacia hidrográfica do Rio São João, onde está uma população de mico-leão-dourado

Figura 6 - Ilustração de Jeca Tatu

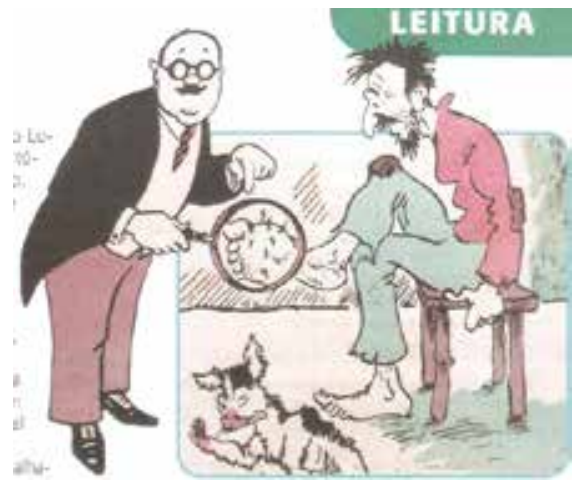

Fonte: MENDONÇA (2013).
Figura 7 - Mapa da Bacia Hidrográfica do Rio São João, no Estado do RJ

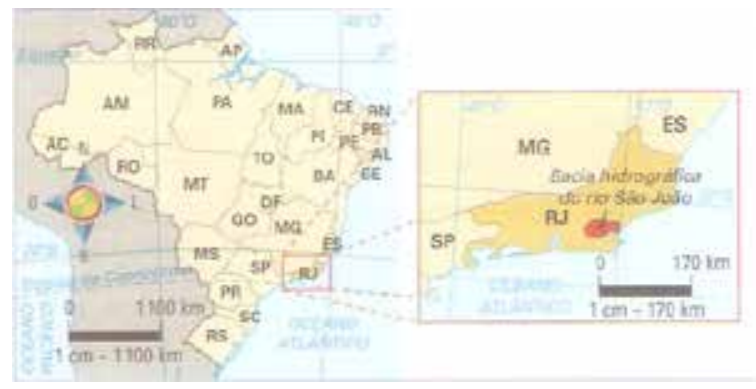

Fonte: OSORIO (2013).

\section{2) Relação entre imagem e texto}

Adotando as categorias propostas por Barthes (1990), Joly (2007) e Pimenta e Gouvêa (2009) a respeito da relação entre o texto verbal e a imagem, percebeu-se um equilíbrio entre diferentes formas em que se deu esta relação. Mesmo entendendo que as categorias estabelecidas não são excludentes, optou-se por destacar aquela que mais se adequou à forma como se deu essa relação. O Quadro 5 descreve estas informações. 
Quadro 5 - Relação entre as imagens e os textos de DC inseridos nos LDs

\begin{tabular}{|l|c|c|c|c|c|c|c|c|}
\hline Relação & $\begin{array}{l}\text { Amabis; } \\
\text { Martho }\end{array}$ & Bröckelmann & $\begin{array}{l}\text { César, } \\
\text { Sezar; } \\
\text { Caldini Jr. }\end{array}$ & Favaretto & $\begin{array}{l}\text { Lopes; } \\
\text { Rosso }\end{array}$ & Mendonça & Osorio & Total \\
\hline $\begin{array}{l}\text { Exclusão } \\
\text { Interação }\end{array}$ & 1 & 1 & 1 & 2 & - & 4 & 1 & 10 \\
\hline $\begin{array}{l}\text { Verdade } \\
\text { Mentira }\end{array}$ & 1 & 2 & 3 & - & - & 1 & 3 & 10 \\
\hline $\begin{array}{l}\text { Interação } \\
\text { Complemen- } \\
\text { taridade }\end{array}$ & - & 1 & - & 1 & 2 & 3 & 2 & 9 \\
\hline Revezamento & - & - & - & 1 & - & 1 & - & 2 \\
\hline Símbolo & - & - & - & - & - & - & 2 & 2 \\
\hline
\end{tabular}

Fonte: Os autores.

Na categoria exclusão/interação a imagem não é excluída pela linguagem, pois esta a acompanha sob a forma de comentários, títulos ou legendas. Nos dez casos classificados nesta categoria, a legenda interage com a imagem ao fornecer informações adequadas sobre esta. Como exemplo para esta categoria, a imagem da Figura 8 é acompanhada pela legenda "Girafa alimentando-se de folhas de acácia, na savana africana"; assim, a linguagem verbal indica corretamente o significado da imagem. Nota-se, também, que a página foi diagramada de modo que a imagem se tornou o seu fundo, envolvendo o texto de forma que apenas a girafa e a acácia, personagens centrais do artigo, estivessem destacadas. Esta é uma estratégia adotada em especial pela coleção de Mendonça (2013), que explora os recursos visuais como forma de atrair o interesse do aluno, em uma diagramação muito semelhante às revistas.

Figura 8 - Girafa alimentando-se de folhas de acácia, na savana africana

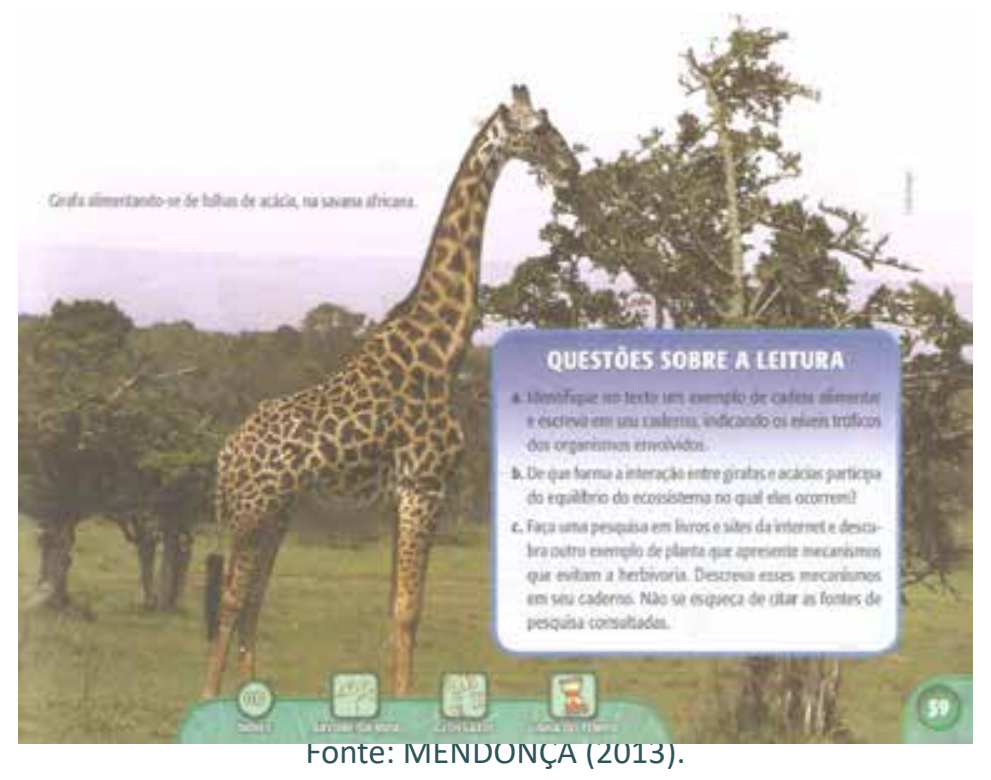

$\mathrm{Na}$ categoria verdade/mentira, a imagem pode ser verdadeira ou mentirosa devido ao que é informado sobre o que representa, podendo esta representação ser ou não verdadeira. Foram identificadas dez imagens cujas legendas indicam informações 
não transmitidas visualmente, de forma que o leitor julgará se tais informações são verdadeiras ou não. Destaca-se a imagem da coleção de Bröckelmann (2013), que apresenta o seguinte comentário: "O caramujo-gigante-africano (Achatina fulica) encontrou no Brasil condições favoráveis para sua proliferação". Embora a imagem represente um conjunto de caramujos-gigantes-africanos (Figura 9), não é possível verificar por meio desta se as demais informações são verdadeiras.

Figura 9 - Fotografia de caramujos-gigantes-africanos

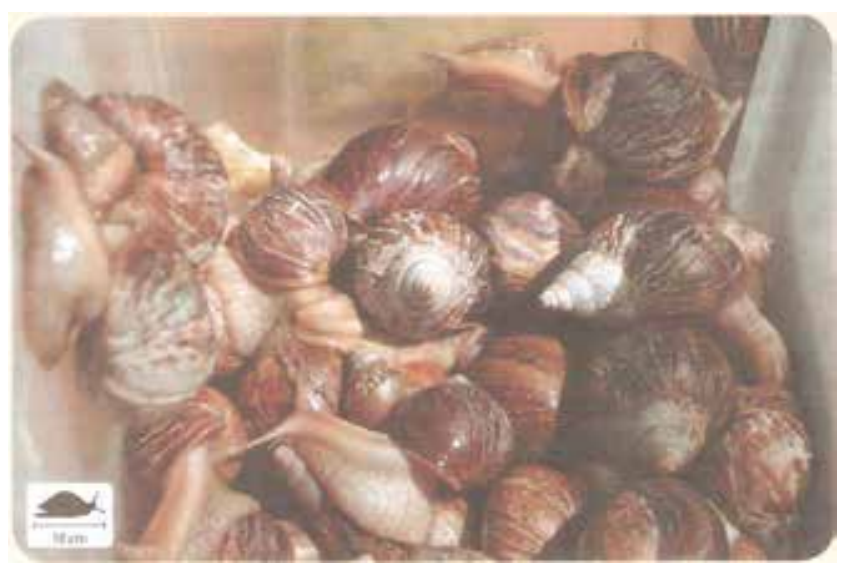

Fonte: BRÖCKELMANN (2013).

Em dez casos verificou-se a relação entre imagem e texto do tipo interação/complementaridade, na qual o texto indica o nível correto de leitura da imagem. Como exemplo, está a suspensão, conforme pode se caracterizar a Figura 10, na qual o título do filme e a sua sinopse criam uma expectativa em relação ao que a imagem representa: no caso o filme "A marcha dos pinguins".

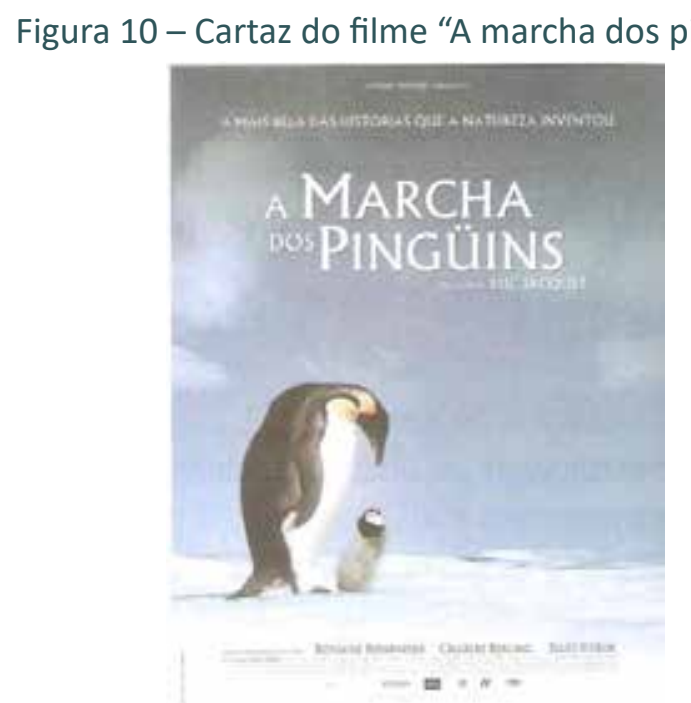

Fonte: LOPES; ROSSO (2013).

A respeito das imagens cuja relação com o texto é do tipo revezamento, quando uma imagem perde o sentido se isolada de outras e do texto, configurando-lhe uma ação, podemos reconhecer a imagem da Figura 5. Nestes casos, os passos do experimento descrito somente ganham sentido em conjunto com o texto ao qual estão associadas. 
Entre as imagens simbólicas, que exprimem noções abstratas, encontra-se a imagem da Figura 4, que apresenta uma filogenia, na qual a leitura da imagem depende da capacidade de interpretar o símbolo que as mesmas representam, ou seja, depende da abstração do leitor ao entender que as linhas da filogenia simbolizam a história evolutiva dos seres vivos e que o traçado de um mapa representa os limites territoriais de uma região geográfica.

\section{3) Conotação fotográfica}

Esta análise ocorreu apenas com as 25 fotografias, identificando que procedimentos de conotação fotográfica estão presentes, isto é, que sentidos são impostos às mensagens inerentes nestas imagens. O Quadro 6 sintetiza as principais informações relacionadas com esta classificação, baseada na obra de Barthes (1990).

Quadro 6 - Procedimentos de conotação fotográfica

\begin{tabular}{|l|c|c|c|c|c|c|c|r|}
\hline Relação & $\begin{array}{l}\text { Amabis; } \\
\text { Martho }\end{array}$ & Bröckelmann & $\begin{array}{l}\text { César, Sezar; } \\
\text { Caldini Jr. }\end{array}$ & Favaretto & $\begin{array}{l}\text { Lopes; } \\
\text { Rosso }\end{array}$ & Mendonça & Osorio & Total \\
\hline Pose & 1 & - & 1 & 3 & 1 & 5 & 2 & 13 \\
\hline Objeto & 1 & 3 & 1 & - & - & 2 & 3 & 10 \\
\hline Fotogenia & - & - & - & 1 & 1 & - & 1 & 3 \\
\hline Sintaxe & - & - & - & 1 & - & - & - & 1 \\
\hline Trucagem & - & - & - & - & 1 & - & - & 1 \\
\hline
\end{tabular}

Fonte: Os autores.

Destaca-se a escolha por fotografias cuja maior conotação é a pose, isto é, que valoriza atitudes estereotipadas. No caso dos animais, estas seriam representações comuns a respeito de seus principais hábitos, como locomoção, alimentação, estado de alerta e cuidado parental. Dos 13 casos identificados, destacamos a imagem da Figura 11 representando a imagem estereotipada de uma abelha visitando uma flor.

Figura 11 - Abelha visitando a flor e entrando em contato com seu pólen

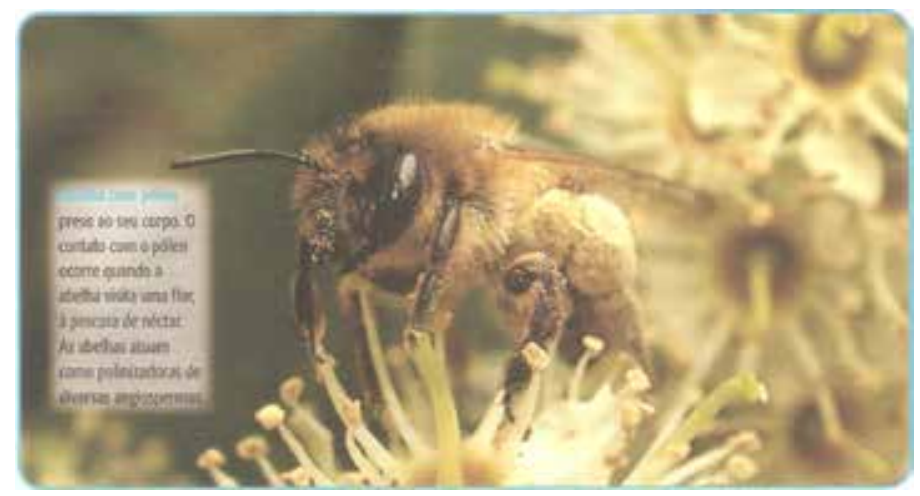

Fonte: MENDONÇA (2013).

Com relação às imagens cuja conotação fotográfica enquadra-se na categoria de objeto, entende-se que a valorização deste torna-se essencial para estabelecer uma sintaxe na leitura da imagem. Entre as dez fotografias classificadas nesta categoria, podemos exemplificar com a imagem que representa o crânio do homem de Piltdown (Figura 12). 
Figura 12 - Crânio do homem de Piltdown

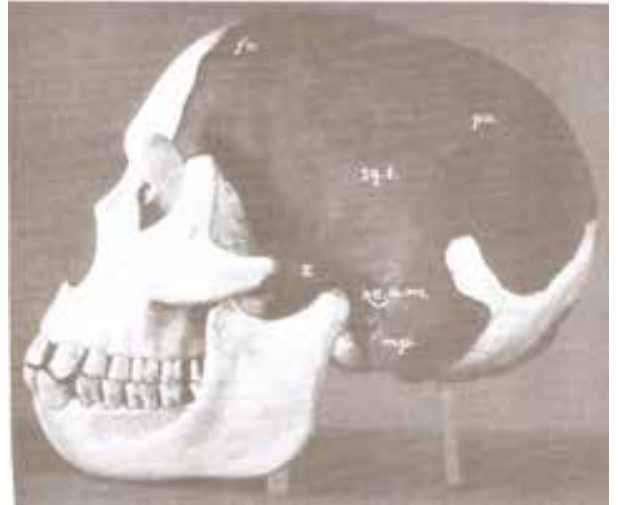

Fonte: AMABIS; MARTHO (2013).

Foram identificadas três imagens que também apresentavam valorização da beleza estética, mesmo que estas pudessem se enquadrar em outras categorias. Este foi o caso da Figura 10, que indica uma opção por registros fotográficos que mostra o belo da natureza. A Figura 13 foi classificada como sintaxe, pois o seu significado encontra-se no nível do encadeamento, isto é, quando diversas imagens estão "encadeadas e dispostas sequencialmente para que cada quadro exprima atitudes e valores que constituam, quando reunidos, novo sentido àquelas imagens" (PIMENTA; GOUVÊA, 2009, p. 3).

Figura 13 - Infográfico sobre a megadiversidade brasileira

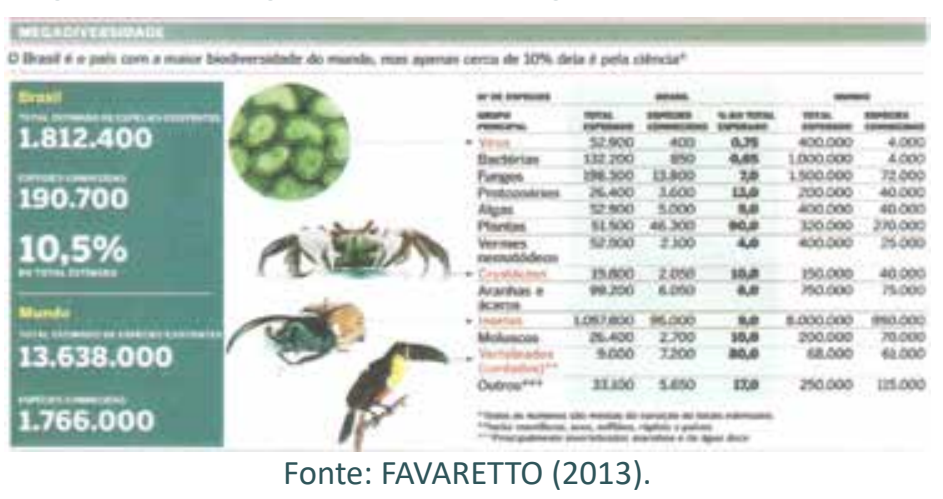

Já a Figura 14, ao comparar o tamanho de uma serpente com uma moeda americana, constitui um caso de trucagem, ao intervir na imagem de modo a aproximar elementos de caráter distinto.

Figura 14 - A menor serpente do mundo comparada a uma moeda americana

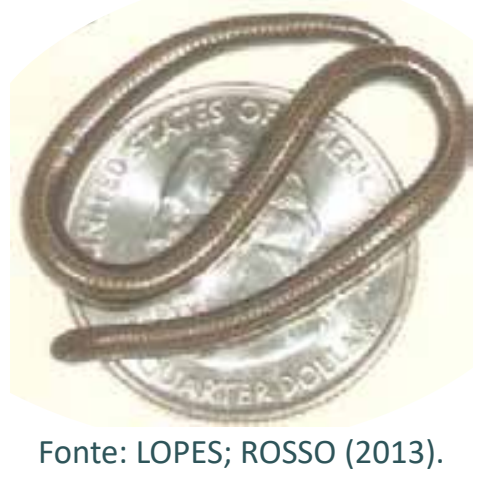




\section{4) Alteração no sentido das imagens}

Comparando as imagens dos textos originais com as inseridas nos LDs, constatou-se que a maior parte das imagens foi alterada, excetuando-se apenas três casos em que as originais foram mantidas. Podemos considerar que estas imagens possuem alguma correspondência com o texto original, como é o caso da Figura 15, inserida na coleção de Amabis e Martho (2013), retratando os lobos do Parque Nacional de Yellowstone (Estados Unidos) e o veado-vermelho, uma de suas presas. Neste caso, pode-se inferir que houve alteração no sentido original da imagem, pois aquela presente no texto original (Figura 16) enfoca apenas a cabeça do lobo, descontextualizando-o de seu ambiente.

Figura 15 - Imagem do texto inserida no LD

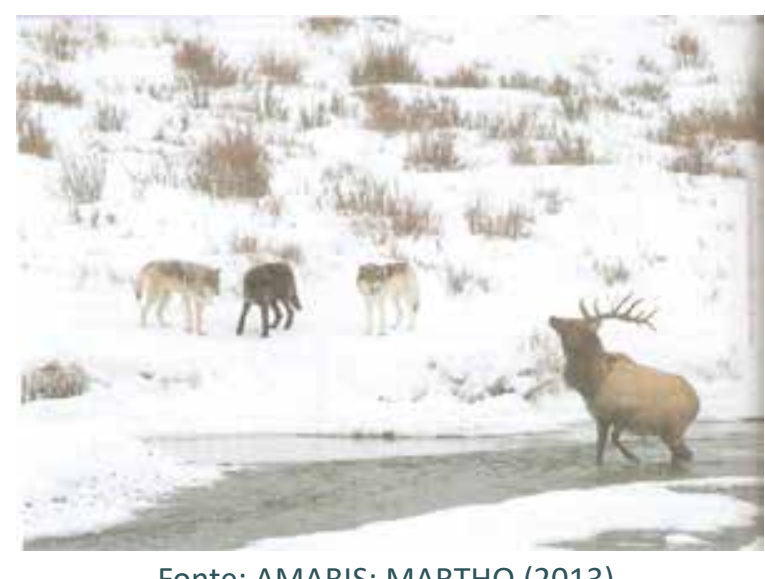

Fonte: AMABIS; MARTHO (2013).
Figura 16 - Imagem do texto de DC original

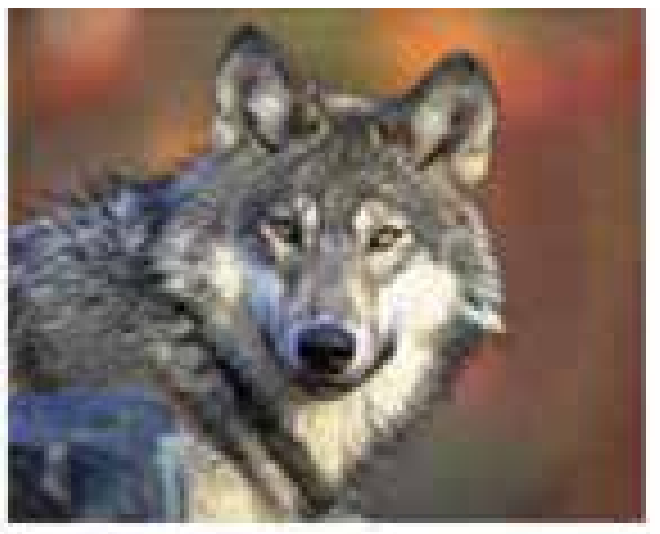

Fonte: A FALTA... (2011).

A Figura 17, inserida na coleção de Mendonça (2013), representa uma ostra aberta, sem pérolas, enquanto aquela inserida no original (Figura 18) apresenta a ostra fechada, fora de um ambiente que se assemelhe ao seu habitat. Esta opção deve-se ao fato de que o texto no LD altera o foco original do texto, que tratava da produção das ostras, para discutir se todos os bivalves deste tipo podem apresentar pérolas em seu interior.

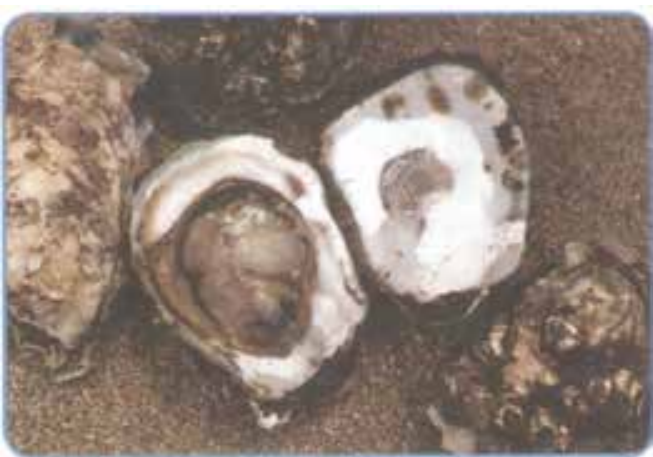

Fonte: MENDONÇA (2013).

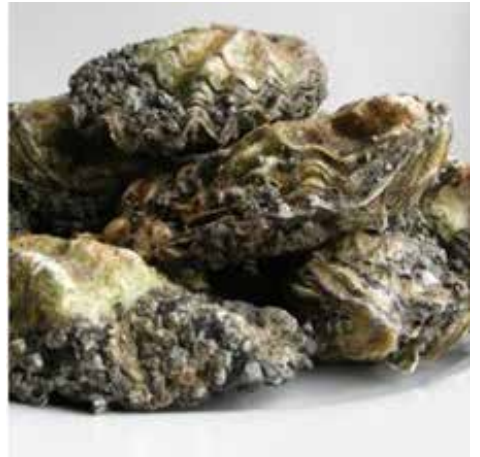

Fonte: DINIZ (2012). 
A Figura 19, presente em Osorio (2013), também resultou em alteração na posição e no enfoque dado ao animal em relação ao ambiente. Enquanto no texto original a aranha encontra-se mais distante, com as bromélias, e o ambiente ao redor compondo o cenário (Figura 20), no texto inserido no LD a aranha aparece em destaque, produzindo sua teia e, aparentemente, preparando um salto.

Figura 19 - Imagem do texto inserida no LD

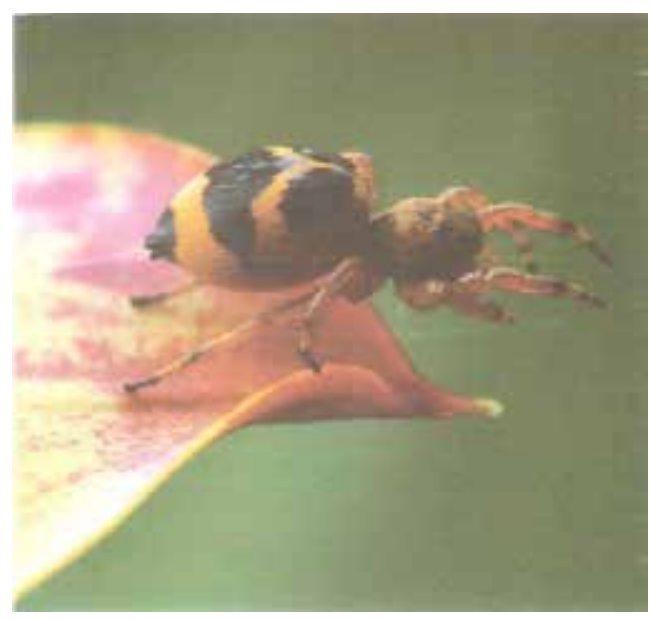

Fonte: OSORIO (2013).
Figura 20 - Imagem do texto de DC original

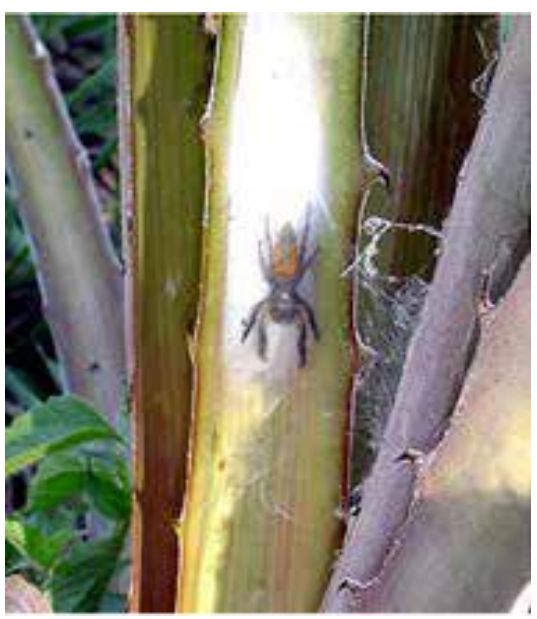

Fonte: KASSAB (2006).

As imagens oriundas dos meios de DC geram discussões que problematizam o seu papel e a intenção dos autores ao inseri-las (GRILLO, 2009; MARANHÃO, 2008; PIMENTA; GOUVÊA, 2009; SOUZA, 2013). Existe uma opção por imagens que, além de estarem adequadas ao texto, sejam inteligíveis para os leitores de acordo com o público-alvo ao qual estas publicações de DC estão voltadas. Em paralelo, diversos autores tratam das imagens no contexto da educação, em especial a sua incorporação pelos LDs de Ciências, analisando diferentes aspectos, como os tipos de imagens selecionadas, características semióticas e os graus de iconicidade presentes (MARTINS et al., 2003; REGO, 2012). Nestes casos, as imagens precisam estar adequadas ao contexto didático, não só pertinente ao conteúdo apresentado, mas também apropriadas para a série de ensino, a faixa etária e a diagramação da coleção didática.

Percebe-se a preferência dos autores e/ou editores das coleções didáticas em adaptar as imagens dos textos de DC ao contexto didático, optando por imagens que ressaltem as informações transmitidas no texto. Na maioria dos casos constata-se que as imagens perderam um caráter meramente ilustrativo, de composição do texto, conforme percebido por Martins, Cassab e Rocha (2001). Embora a diversidade de imagens seja baixa - maioria de fotografias - estas representam os animais de forma contextualizada, em seus ambientes, realizando ações típicas de seus comportamentos. Ainda que sejam ações estereotipadas, ajudam a explicar aspectos descritos nos textos, como a polinização de abelhas, os hábitos alimentares dos lobos e das girafas, o cuidado parental e a postura de ataque das aranhas. Por outro lado, é prudente ter cuidado na seleção destas imagens para que elas não endossem possíveis erros históricos e conceituais comumente encontrados no corpus textual (BIZZO, 2000). 
As imagens com finalidades classificatórias, analíticas ou narrativas ocupam grande parte da estrutura didática do texto, principalmente nos LDs das séries mais avançadas, como os anos finais do Ensino Fundamental e o Ensino Médio (MARTINS et al., 2003; MARTINS; GOUVÊA; PICCININI, 2005). Ao mesmo tempo, observa-se uma tendência à redução do nível de iconicidade das imagens, à medida que ocorre uma redução do número de fotografias, que são a representação da realidade naturalista, e um aumento da quantidade de gráficos, que exigem maior abstração (PRALON, 2012; REGO, 2012). Percebeu-se, contudo, nesta análise, certo distanciamento dos textos de DC inseridos nos textos didáticos do Ensino Médio, na medida em que ocorre maior opção por fotografias, com características conceituais simbólicas e naturalistas. Há divergência, principalmente, com as imagens do corpus didático dos capítulos destinados ao estudo dos animais, com maior quantidade de imagens classificatórias ou analíticas. Conclui-se que a preferência dos autores e/ou editores ao inserirem estes tipos de imagens deve-se à possibilidade de ilustrar e complementar informações dos textos de DC, sem outras finalidades didáticas, reforçando a característica destes textos de DC inseridos nos LDs enquanto híbridos do ponto de vista discursivo.

\section{CONSIDERAÇÕES FINAIS}

Os dados levantados por esta análise corroboram a intenção dos autores e/ou editores dos LDs de apresentar materiais de DC de forma híbrida, mesclando componentes jornalístico-divulgativos com didáticos. Acredita-se que, no momento de incorporar a parte textual do material de DC, inclusive realizando modificações neste, os autores e/ ou editores devem ter observado questões relacionadas à economia de espaço - o que justificaria a eliminação de imagens - ou o significado que aquela imagem transmite. 0 que não está claro é se estas mudanças acarretam algum prejuízo - ou benefício - para a leitura do texto.

Um próximo passo na trilha desta pesquisa seria identificar, junto a alunos e professores, que diferenças existem nestas imagens que possam alterar de forma significativa o processo de ensino-aprendizagem, uma vez que tais materiais de DC podem ser utilizados em sala de aula com viés pedagógico. Desta maneira, isto poderia provocar uma reflexão que fizesse com que os autores e/ou editores de materiais didáticos, sejam estes os próprios LDs ou, inclusive, materiais on-line, tivessem maior orientação em relação à maneira com a qual se apropriam de materiais divulgativos que permanecem profundamente relevantes na atual conjuntura.

\section{REFERÊNCIAS}

A FALTA dos grandes predadores. Agência Fapesp, São Paulo, 19 jul. 2011. Disponível em: agencia.fapesp. br/14195. Acesso em: 14 set. 2015.

AMABIS, J. M.; MARTHO, G. R. Biologia em contexto. 1. ed. São Paulo: Moderna, 2013.

BARTHES, R. O óbvio e o obtuso: ensaios críticos III. Rio de Janeiro: Nova Fronteira, 1990.

BELLINI, L. M. Avaliação do conceito de evolução nos livros didáticos. Estudos em Avaliação Educacional, v. 17, n. 33, p. 7-28, 2006.

BIZZO, N. Falhas no ensino de ciências. Ciência Hoje, Rio de Janeiro, v. 27, n. 159, p. 26-31, abr. 2000.

BIZZO, N. Novas bases da biologia. 2. ed. São Paulo: Ática, 2013.

BRASIL. Ministério da Educação. Guia de livros didáticos: PNLD 2015 - Biologia - Ensino Médio. Brasília: MEC; SEB, 2014. 
BRÖCKELMANN, R. H. Conexões em biologia. 1. ed. São Paulo: Moderna, 2013.

CARVALHO, C. P. Divulgação Científica nas revistas Scientific American Brasil e Superinteressante. Informação \& Informação, Londrina, v. 15, n. especial, p. 43-55, 2010.

CÉSAR S. JR.; SEZAR S.; CALDINI JR., N. Biologia. 11. ed. São Paulo: Saraiva, 2013.

DINIZ, I. N. Ostras podem acumular agentes causadores de doenças, comprova pesquisa. Pesquisa Fapesp, São Paulo, 28 mar. 2012. Disponível em: revistapesquisa.fapesp.br/ 2012/03/28/ostras-podem-acumular-agentes-causadores-de-doenças-comprova-pesquisa. Acesso em: 20 jun. 2016.

EL-HANI, C. N.; ROQUE, N.; ROCHA, P. L. B. Livros Didáticos de Biologia do Ensino Médio: Resultados do PNLEM/2007. In: ENCONTRO NACIONAL DE PESQUISA EM EDUCAÇÃO EM CIÊNCIAS, 6., 2007. Florianópolis. Atas [...]. Florianópolis: Abrapec, 2007.

FAVARETTO, J. A. Biologia unidade e diversidade. 1. ed. São Paulo: Saraiva, 2013.

GALIETA-NACIMENTO, T. O discurso da divulgação científica no livro didático de ciências: características, adaptações e funções de um texto sobre clonagem. Revista Brasileira de Pesquisa em Educação em Ciências, v. 5, n. 2, p. 1-13, 2005.

GARCIA, P. S.; BIZZO, N. A pesquisa em livros didáticos de ciências e as inovações no ensino. Educação em Foco, a. 13, n. 15, p. 13-35, 2010.

GARRÉ, B. H.; HENNING, P. C. Visibilidades e enunciabilidades do dispositivo da educação ambiental: a Revista Veja em exame. Alexandria - Revista de Educação em Ciência e Tecnologia, v. 8, n. 2, p. 53-74, jun. 2015.

GOUVÊA, G.; MARTINS, I. Imagens e Educação em Ciências. In: ALVES, N.; SGARBI (org.). Imagens e espaços da escola. 1. ed. Rio de Janeiro/RJ: D P \& A, 2001. p. 41-57.

GRILLO, S. Dimensão verbo-visual de enunciados de Scientific American Brasil. Bakhtiniana, São Paulo, v. 1, n. 2, p. 8-22, jul./dez. 2009.

GÜLLICH, R. I.; EMMEL, R.; PANSERA-DE-ARAÚJO, M. C. Interfaces da pesquisa sobre o livro didático de Ciências. In: ENCONTRO NACIONAL DE PESQUISA EM EDUCAÇÃO EM CIÊNCIAS, 7., 2009. Florianópolis. Atas [...]. Florianópolis: Abrapec, 2009.

JOLY, M. Introdução à análise da imagem. Campinas: Papirus, 1996.

KASSAB, A. A bromélia dá a casa, e a aranha, a comida. Jornal da Unicamp, 3 dez. 2006. Disponível em: www.unicamp.br/unicamp/unicamp_hoje/ju/novembro2006/ ju345pag12. html. Acesso em: 28 jul. 2016.

KRESS, G.; VAN LEEUWEN, T. Reading images: the grammar of visual design. 1. ed. London: Routledge, 1996.

LINHARES, S.; GEWANDSZNAJDER, F. Biologia hoje. 2. ed. São Paulo: Ática, 2013.

LOPES, S.; ROSSO, S. Bio. 2. ed. São Paulo: Saraiva, 2013.

MARANHÃO, C. O poder da imagem fotográfica: uma análise das imagens publicadas nas revistas Veja e IstoÉ de Luiz Inácio Lula da Silva durante as campanhas presidenciais de 1989 e 2002. Cenários da Comunicação, São Paulo, v. 7, n. 1, p. 13-22, 2008.

MARTINS, I. O papel das representações visuais no ensino e na aprendizagem de ciências. In: ENCONTRO NACIONAL DE PESQUISA EM EDUCAÇÃO EM CIÊNCIAS, 1., 1997, Águas de Lindóia. Atas... Aguas de Lindóia: ABRAPEC, 1997.

MARTINS, I.; CASSAB, M.; ROCHA, M. Análise do processo de re-elaboração discursiva de um texto de divulgação científica para um texto didático. Revista Brasileira de Pesquisa em Educação em Ciências, v. 1, n. 3, p. 1-9, 2001.

MARTINS, I.; DAMASCENO, A. Uma análise das incorporações de textos de divulgação científica em livros didáticos de ciências. In: ENCONTRO DE PESQUISA EM ENSINO DE FÍSICA, 8., 2002. São Paulo. Atas [...]. São Paulo, 2002.

MARTINS, I.; GOUVÊA, G.; PICCININI, C. Aprendendo com imagens. Ciência e Cultura, São Paulo, a. 57, n. 4, p. 38-40, out./dez. 2005.

MARTINS, I. et al. Uma análise das imagens nos livros didáticos de ciências para o Ensino Fundamental. In: ENCONTRO NACIONAL DE PESQUISA EM EDUCAÇÃO EM CIÊNCIAS, 4., 2003. Bauru. Atas [...]. Bauru: Abrapec, 2003.

MEGID-NETO, J.; FRACALANZA, H. O livro didático de ciências: problemas e soluções. Ciência \& Educação, v. 9, n. 2, p. 147-157, 2003.

MENDONÇA, V. L. Biologia. 2. ed. São Paulo: AJS, 2013. 
MONERAT, C. A. A.; ROCHA, M. B. Análise da percepção de estudantes de Graduação da área da saúde sobre o tema Biologia Celular. Revista de Ensino de Bioquímica, v. 13, n. 1, p. 27-44, 2015.

NÚÑEZ, I. B. et al. A seleção dos livros didáticos: um saber necessário ao professor: o caso do ensino de Ciências. OEI - Revista Iberoamericana de Educación, v. 33, n. 1, p. 1-15, 2003.

OSORIO, T. C. (ed.). Ser protagonista - biologia. 2. ed. São Paulo: SM, 2013.

PICCININI, C. L. Imagens no ensino de ciências: uma imagem vale mais do que mil palavras. In: MARTINS, I.; GOUVÊA, G; VILANOVA, R. (ed.). O livro didático de Ciências: contextos de exigência, critérios de seleção, práticas de leitura e uso em sala de aula. 1. ed. Rio de Janeiro: Ed. Faperj, 2012. p. 159-170.

PIMENTA, M.; GOUVÊA, G. Imagens na divulgação científica em jornais de grande circulação no Brasil. In: ENCONTRO DE PESQUISA EM EDUCAÇÃO EM CIÊNCIAS, 7., 2009. Florianópolis. Atas [...]. Florianópolis: Abrapec, 2009.

PRALON, L. Imagem e produção de sentido: as fotografias no livro didático. In: MARTINS, I.; GOUVÊA, G.; VILANOVA, R. (ed.). O livro didático de ciências: contextos de exigência, critérios de seleção, práticas de leitura e uso em sala de aula. 1. ed. Rio de Janeiro: Editora Faperj, 2012. p. 159-170.

REGO, S. C. R. Imagens e ensino de física: análise de livros didáticos utilizados em um curso de Licenciatura. In: MARTINS, I.; GOUVÊA, G.; VILANOVA, R. (ed.). O livro didático de ciências: contextos de exigência, critérios de seleção, práticas de leitura e uso em sala de aula. 1. ed. Rio de Janeiro: Editora Faperj, 2012. p. 171-186.

ROCHA, M. Textos de divulgação científica na sala de aula: a visão do professor de ciências. Revista Augustus, v. 14, n. 29, p. 24-34, fev. 2010.

SOUZA, P. H. R. Análise da sistemática filogenética na Revista Scientific American Brasil. 2013. Dissertação (Mestrado em Ciência, Tecnologia \& Educação) - Cefet/RJ, Rio de Janeiro, 2013.

SOUZA, P. H. R. Análise dos textos de divulgação científica referentes à biologia animal em livros didáticos de biologia para o Ensino Médio. 2017. Tese (Doutorado em Ciência, Tecnologia \& Educação) - Cefet/RJ, Rio de Janeiro, 2017.

SOUZA, P. H. R.; ROCHA, M. B. Análise do processo de reelaboração discursiva na incorporação de um texto de divulgação científica no livro de ciências. Revista Brasileira de Educação em Ciência e Tecnologia, v. 7, n. 1, p. 53-69, jan./abr. 2014a.

SOUZA, P. H. R.; ROCHA, M. B. Abordagem da mídia impressa em periódicos da área de Ensino de Ciências". In: SIMPÓSIO NACIONAL DE ENSINO DE CIÊNCIA E TECNOLOGIA, 4., 2014. Ponta Grossa. Anais [...]. Ponta Grossa, 2014b.

SOUZA, P. H. R.; ROCHA, M. B. Sistemática filogenética em revista de divulgação científica: análise da Scientific American Brasil. Alexandria - Revista de Educação em Ciência e Tecnologia, v. 8, n. 1, p. 75-99, maio 2015a.

SOUZA, P. H. R.; ROCHA, M. B. Caracterização dos textos de divulgação científica inseridos em livros didáticos de Biologia. Investigações em Ensino de Ciências, v. 20, n. 2, p. 126-137, 2015b.

SOUZA, P. H. R.; ROCHA, M. B. Análise da linguagem de textos de divulgação científica em livros didáticos: contribuições para o ensino de biologia. Ciência \& Educação, v. 23, n. 2, p. 321-340, 2017.

SOUZA, P. H. R.; ROCHA, M. B. O caráter híbrido dos textos de divulgação científica inseridos em livros didáticos. Ciência \& Educação, v. 24, n. 4, p. 1.043-1.063, 2018.

VASCONCELOS, S. D.; SOUTO, E. O livro didático de ciências no Ensino Fundamental - proposta de critérios para análise do conteúdo zoológico. Ciência \& Educação, v. 9, n. 1, p. 93-104, 2003. 